\title{
Ectoparasite burdens of the Damaraland mole-rat (Fukomys damarensis) from Southern Africa
}

\author{
${ }^{1}$ Heike Lutermann, ${ }^{1}$ Tegan Carpenter-Kling, Edward A. Ueckermann† $\dagger$, ${ }^{1}$ Gundula Gutjahr, and ${ }^{1}$ Nigel C. \\ Bennett
}

${ }^{1}$ Department of Zoology and Entomology, University of Pretoria, Pretoria 0002, South Africa. *ARCPlant Protection Research Institute, Private Bag X134, Queenswood, Pretoria, 0121, South Africa.

$\uparrow$ School of Environmental Sciences and Development, Potchefstroom University, Potchefstroom, 2520, South Africa.Correspondence should be sent to: hlutermann@zoology.up.ac.za

ABSTRACT: Damaraland mole-rats (Fukomys damarensis) of the family Bathyergidae are widely distributed subterranean rodents in sub-Saharan Africa. No parasites have ever been reported for this species and only 1 ectoparasite is described for the entire genus. In the current study ectoparasites were collected from individuals captured at 3 localities in South Africa and Namibia to document the ectoparasite community of $F$. damarensis, investigate their aggregation patterns and evaluate the influence of season on ectoparasite burden. A total of 2,071 arthropods from 9 mite taxa and 1 louse species (Eulinognathus hilli) were collected from 293 hosts sampled. Of these 5 mite species (Androlaelaps scapularis, A. capensis, A. tauffliebi, Radfordia sp. and unidentified chiggers) and the louse were parasites while the remainder were soil mites. All ectoparasites were highly aggregated and the species richness as well as the prevalence and abundance of 4 of them were significantly greater in summer compared to winter, possibly as a result of seasonal changes in rainfall patterns affecting the ectoparasites and/or host behavior.

It is commonly observed that parasites exhibit an aggregated distribution within a host population with a small proportion of the host population sustaining the majority of parasites (Wilson et al., 2001; Poulin, 2007). Such heterogeneities may be generated by a suite of abiotic and biotic factors including rainfall and temperature often resulting in seasonal variation in parasite burden (Wilson et al., 2001; Altizer et al., 2006). The influence of abiotic factors appears to be particularly pronounced in arthropod ectoparasites that do not spend their entire lifecycle on the host (Vinarski et al., 2007; Krasnov et al., 2008; Korallo-Vinarskaya et al., 2009). However, seasonal changes in parasite burden may also be linked to changes in host behavior or physiology. For instance, breeding dispersal may lead to increases in interspecific encounter rates or males may increase the area they are roaming both of which may facilitate parasite transmission (Scantlebury et al., 2010). In addition, seasonally changing reproductive investment may result in physiological trade-offs between reproduction and parasite defense lowering host resistance during breeding events (Christe et al., 2000; Klein, 2004).

The subterranean, hystricomorph rodent family Bathyergidae (African mole-rats) is widely distributed across sub-Saharan Africa (Bennett and Faulkes, 2000). It is well known for the variance in the degree of sociality observed in this family while it remains comparatively poorly studied with respect to its parasite fauna (Scharff et al., 1997; Viljoen et al., 2011; Archer et al., 2014). In fact, for Damaraland mole-rats (Fukomys damarensis), 1 of only 2 eusocial bathyergids, the imbalance between studies of their reproductive biology and parasite fauna is particularly pronounced (Bennett and Faulkes, 2000). To date there is only a single study of their parasites available that suggests that this species is devoid of any ectoparasites (De Graaff, 1972). However, the Zumpt collection of parasitic mites curated at the Arachnida Collection of Biosystematics at the Agricultural Research Council (ARC)-Plant Protection Research Institute in Pretoria, South Africa includes unpublished records of Androlaelaps scapularis from Gobabeb in Namibia and a location indicated as 'Island off Boro' (presumably in Botswana) as well as for Androlaelaps capensis from Xheuga Island in Botswana for $F$. damarensis. Similarly, a lack of ectoparasites was recorded for other members of this genus (Scharff et al., 1997) and unidentified mites were reported for a single individual of the 
giant mole-rat (Fukomys mechowii) in a study of their natural history (Scharff et al., 2001) while a mite species of the genus Androlaelaps has been described from F. mechowii (Till, 1963). The Zumpt collection contains additional specimens of Androlaelaps capensis collected from Fukomys darlingi at unspecified locations in Zimbabwe. This apparent lack of ectoparasites for the genus Fukomys contrasts markedly with the high prevalence of ectoparasitic arthropods found in bathyergid species of the genus Cryptomys, including Androlaelaps scapularis and $A$. capensis, although with only 4 to 6 species the ectoparasite species diversity observed was low (Viljoen et al., 2011; Archer et al., 2014). In the current study, we screened a large number $F$. damarensis individuals for ectoparasites to (1) either confirm or refute a lack of ectoparasites for this species. In addition, if ectoparasites were retrieved, (2) we aimed to determine the degree of aggregation among these ectoparasites. Lastly, (3) we evaluated the effects of season on ectoparasite burden.

\section{MATERIALS AND METHODS}

The study species has a wide geographic distribution including most of Botswana, central and northern Namibia, smaller strips of northeastern Angola, northwestern Zambia and western Zimbabwe as well as the northern and northwestern Cape Province of South Africa (Bennett and Faulkes, 2000). Animals were captured at 3 sites representing the southern and western edges of the distributional range of $F$. damarensis: Dordabis, Namibia $\left(22^{\circ} 58^{\prime} \mathrm{S}\right.$, $\left.17^{\circ} 41^{\prime} \mathrm{E}\right)$, Hotazel, Northern Cape, South Africa $\left(27^{\circ} 17^{\prime} \mathrm{S}, 22^{\circ} 58^{\prime} \mathrm{E}\right)$ and Tswalu Kalahari Game Reserve, Northern Cape, South Africa (2722'S, $\left.22^{\circ} 19^{\prime} \mathrm{E}\right)$. Capture trips were conducted during both the austral winter (January to March) and summer (June to August). Mole-rats were sampled once during October 2004 at Tswalu, twice at Dordabis during April and September 2001, respectively, and 4 times in Hotazel during January 2001, July 2002, April and August 2012 using modified Hickman live-traps baited with sweet potato that were placed into exposed tunnels and checked every 2 to $3 \mathrm{hr}$ from dusk till dawn. Captured individuals were kept in plastic crates with their colony mates on a soil layer and maintained on sweet potatoes until processed. Within a week of capture animals were briefly anaesthetized using halothane and a modified washing technique was employed to remove ectoparasites (for details see Archer et al., 2014). This procedure was standardized to obtain comparable results and each animal was dipped 20 times in ca. $500 \mathrm{ml}$ of soapy water, dried and allowed to recover before the entire group was eventually released at their point of capture. Wash samples were filtered through a No. 25 U.S. Standard Sieve (710 micron screen) and screened for ectoparasites under a binocular dissection microscope. Any ectoparasites retrieved were stored in $70 \%$ ethanol until prepared for identification following standard protocols. Specimens were counted and identified using reference keys and handbooks (Till, 1963; Ledger, 1980; Baker, 1999). Voucher specimens were deposited with the South African Agricultural Research Council in Pretoria, South Africa accession numbers: Acy: 15/144- Acy: 15/148.

We calculated the prevalence (proportion of hosts in populations infested) and abundance for each arthropod species retrieved (mean number of parasites on a host, Bush et al., 1997). In addition, as a measure of the aggregation, we calculated the dispersion index $(D)$ for each species found on more than 1 host individual (see results section). Ranging from 0 to 1 increasing values of $D$ indicate higher degrees of aggregation in the parasite population. All of these parameters were determined using the program Quantitative Parasitology 3.0 (Rósza et al., 2000). Furthermore, we calculated the species richness (number of parasite species per host). Ectoparasite prevalence, abundance and species richness were compared between seasons and the sexes using $\chi^{2}$-tests and Mann-Whitney$\mathrm{U}$ tests, respectively. No information on host sex was available for 97 animals caught in Dordabis and hence the latter analyses could only be carried out with a reduced sample size. All analyses were carried out in SPSS v21 and results are reported as means $\pm \mathrm{SE}$.

\section{RESULTS}

A total of 293 Damaraland mole-rats (summer: $n$ $=143$, winter: $\mathrm{n}=150$ ) were sampled throughout the course of this study. From these 2,071 individual arthropods were collected and the 
overall prevalence was $37.2 \%$. They were comprised of 9 mite taxa and 1 louse species (Table I). However, 4 of the mite taxa were nonparasitic soil mites (Ameroseius sp., Macrocheles sp., Acaroiodea and Histiostomididae) while only the remaining 5 mites and the single louse species are parasites. Parasitized hosts sustained between 1 and 5 ectoparasite species with the majority of hosts being infested with a single species $(22.5 \%)$ while more than 1 ectoparasite species was recovered from the remaining hosts (13.0\%). Species richness was significantly greater during summer $(0.85 \pm 0.10)$ compared to winter $(0.43$ $\pm 0.07, \mathrm{U}=12,716.5, \mathrm{p}=0.001)$. The mite Androlaelaps scapularis was the most prevalent and abundant species found followed by the louse Eulinognathus hilli (Table II). However, the abundance of $E$. hilli was substantially lower than that of A. scapularis. Similarly, 2 other Androlaelaps spp. occurred at lower abundances than $A$. scapularis with $A$. capensis being almost 20 times less abundant Table II). Unidentified trombiculid larvae (chiggers) were the only other ectoparasite species recovered that occurred at a similar abundance as Androlaelaps tauffliebi, although their prevalence was lower Table II). Radfordia sp. had the lowest prevalence and abundance of the ectoparasite taxa Table II).

With the exception of $A$. tauffliebi, all of the ectoparasites recovered from $F$. damarensis were significantly more prevalent (Fig. 1A) and abundant (Fig. 1B) during summer compared to winter (Table III). The low prevalence of Radfordia sp. precluded any meaningful statistical analyses of its seasonal patterns, however, of the 5 individuals infested, 3 were caught in winter and 2 in summer. In addition, the abundance of Radfordia sp. appeared similar in both seasons (Fig. 1B). Host sex did not affect either the prevalence or the abundance of any of the ectoparasite species considered (Table III). Similarly, species richness did not differ significantly between the sexes $(\mathrm{U}=4,915.0, \mathrm{p}=$ 0.770 ). The index of discrepancy was high for all arthropod species exceeding a prevalence of 3\% (Table II). It was significantly negatively correlated with prevalence $\left(\mathrm{R}_{\mathrm{S}}=-0.905, \mathrm{p}=\right.$ $0.004)$ but not abundance $\left(\mathrm{R}_{\mathrm{S}}=-0.524, \mathrm{p}=\right.$ 0.099).

\section{DISCUSSION}

Our study recovered 10 arthropod taxa of which only 6 are known to be parasitic on vertebrates. This is rather low compared to other African rodents (de Graaff, 1981; Fagir et al., 2014) and may be the result of the subterranean life-style of the study species that could limit exposure to parasites (Viljoen et al., 2011; Archer et al., 2014). However, the ectoparasite species richness greatly exceeds that observed for any member of the genus Fukomys in previous studies (De Graaff, 1972; Scharff et al., 1997, 2001). In light of the low overall ectoparasite prevalence and high aggregation levels found in the current study the number of animals sampled in earlier studies may have been too small to recover ectoparasites. At the same time, with 6 species the ectoparasite species diversity of $F$. damarensis is equal to or slightly higher than that reported for Cryptomys hottentotus hottentotus and Cryptomys hottentotus pretoria from South Africa with 6 and 4 species, respectively (Viljoen et al., 2011; Archer et al., 2014). Hence, $F$. damarensis appears to sustain one of the greatest ectoparasite species diversities reported for any bathyergid to date.

Although the species diversity was greater in the study species than in some other bathyergids the overall ectoparasite prevalence was markedly lower in the study species compared to a prevalence between 65.3 and $78.4 \%$ reported for the 2 Cryptomys spp. (Viljoen et al., 2011; Archer et al., 2014). Similarly, with an abundance of 8.86 and 14.1 other Cryptomys spp. sustained substantially higher abundances of the dominant ectoparasite species than $F$. damarensis. Interestingly, $A$. scapularis was the dominant ectoparasite species for all 3 social bathyergids with $A$. capensis present in much lower numbers further supporting the hypothesis that both of these ectoparasite species are host specific for bathyergids (Archer et al., 2014). Androlaelaps tauffliebi was described as a parasite of Fukomys mechowii from Angola (Till, 1963) and no other records exist. This could indicate that $A$. tauffliebi is host specific at the genus level as has been suggested for A. cryptomius at the species level (Archer et al., 2014). The sampling locations in the current study represent its southernmost distribution recorded to date. 
Only 2 species of the genus Radfordia were previously reported from bathyergids with Radfordia rotunda being recovered from Cryptomys spp. in the Kwazulu-Natal Province (Zumpt, 1961) while Radfordia ensifera parasitized $C . h$. hottentotus in the Western and Northern Cape Provinces (Archer et al., 2014). The low prevalence and abundance recorded for Radfordia sp. in the current study may either suggest that the study localities represent the edge of the distributional range of either of these species or that $F$. damarensis harbors an entirely different species. The louse E. hilli is host specific for bathyergids and was previously reported from Cryptomys spp. from the Northern Cape and Natal Provinces of South Africa as well as from Botswana (Ledger, 1980; Durden, 1991). The locality in Namibia sampled in the current study thus represents its westernmost distribution. Four species of chiggers are known from bathyergids, 3 from Cryptomys hottentotus from the Kwazulu-Natal Province of South Africa (Schoutedimnichia crocidura, Gahrliepia nana, and Acamatacarus polydiscum) as well as 1 from Heterocephalus glaber from East Africa (Euschöngastia bottegi), however, according to Zumpt (1961) the latter species is somewhat questionable. In addition, a single unidentified chigger was retrieved from $C$. h. hottentotus by Archer et al. (2014). The current study suggests that chiggers may be more common parasites of bathyergids than previously suggested but a lack of expertise of this family in the country did not allow us to identify the species sustained by $F$. damarensis.

All of the ectoparasite species infesting $F$. damarensis were highly aggregated as is characteristic for many parasite species (Wilson et al., 2001; Poulin, 2007) and 4 of the 6 species showed marked seasonal patterns with prevalence and abundance being significantly greater during the summer than in winter. Such seasonal variation in ectoparasite burden is common across host species and is frequently related to abiotic factors affecting arthropod parasites (Krasnov et al., 2008; KoralloVinarskaya et al., 2009). It has also previously been reported for other bathyergids (Viljoen et al., 2011; Archer et al., 2014). However, while burdens peaked in summer for $C$. h. pretoriae they were greatest in winter for $C$. h. hottentotus suggesting that temperature plays a minor role in this pattern. In contrast, $C . h$. pretoriae experiences summer rainfall similar to $F$. damarensis, while $C . h$. hottentotus inhabits a winter rainfall region and peaks in burden coincide with high rainfall. Increases in rainfall also trigger dispersal behavior in the study species (Hazell et al., 2000; Young et al., 2010) suggesting that in addition to direct effects of rainfall on the ectoparasites found to parasitize $F$. damarensis, increases in inter-colony dispersal may promote parasite transmission.

In conclusion, the current study greatly extended our knowledge of ectoparasite species parasitizing the genus Fukomys with 5 species of mites and 1 louse exploiting $F$. damarensis. Four of these species appear to be specialists for the family Bathyergidae with 1 being potentially genus-specific. All of these species were highly aggregated across the host population and the prevalence and abundance of 4 of these was significantly higher during the wet summer compared to the dry winter possibly as a result of either increases in humidity and/or rainfallinduced changes in host dispersal behavior.

\section{ACKNOWLEDGMENTS}

We thank the owners for access to their properties and Northern Cape Conservation and the Namibian Department of Nature Conservation and Mike Griffin for issuing capture permits. This research was approved by the Animal Ethics Committee of the University of Pretoria. We are indebted to a large number of volunteers as well as Eddie Green for his help with louse identification. Research was funded by the NRF-SARChI chair for Mammalian Behavioural Ecology and Physiology, the NRF and the University of Pretoria.

\section{LITERATURE CITED}

Altizer, S., A. Dobson, P. Hosseini, P. Hudson, M. Pascual, and P. Rohani. 2006. Seasonality and the dynamics of infectious diseases. Ecology Letters 9: 467-484.

Archer, E. K., N. C. Bennett, E. A. Ueckermann, and H. Lutermann. 2014. Ectoparasite burdens of the common mole-rat (Cryptomys hottentotus hottentotus) from the Cape Provinces of South Africa. Journal of Parasitolology 100: 79-84. 
Baker, A. S. 1999. Mites and ticks of domestic animals. An identification guide and information source. Natural History Museum, London, U.K., $240 \mathrm{p}$.

Bennett, N. C., and C. G. Faulkes. 2000. African mole-rats: Ecology and eusociality. Cambridge University Press, Cambridge, U.K., 291 p.

Bush, A.O., K. D. Lafferty, J. M. Lotz, and A. W. Shostak. 1997. Parasitology meets ecology on its own terms: Margolis et al revisited. Journal of Parasitology 83: 575-583.

Christe, P., R. Arlettaz, and P. Vogel. 2000. Variation in intensity of a parasitic mite (Spinturnix myoti) in relation to the reproductive cycle and immunocompetence of its bat host (Myotis myotis). Ecology Letters 3: 207-212.

De Graaff, G. 1972. On the mole-rat (Cryptomys damarensis) (Rodentia) in the Kalahari Gemsbok National Park. Koedoe 15: 25-35.

1981. The rodents of southern Africa. Butterworths, Durban, South Africa, 267 p.

Durden, L. A. 1991. New records of sucking lice (Insecta: Anoplura) from African mammals. Journal of African Zoology 105: 331-342.

Fagir, D. M., E. A. Ueckermann, I.G. Horak, N.C. Bennett and H. Lutermann. 2014. The Namaqua rock mouse (Micaelamys namaquensis) as a potential reservoir and host of arthropod vectors of diseases of medical and veterinary importance in South Africa. Parasites and Vectors 7: 366.

Hazell, R. W. A., N. C. Bennett, J. U. M. Jarvis and M. Grif. 2000. Adult dispersal in the cooperatively breeding Damaraland mole-rat (Cryptomys damarensis): a case study from the Waterberg region of Namibia. Journal of Zoology 252: 19-25.

Klein, S. L. 2004. Hormonal and immunological mechanisms mediating sex differences in parasite infection. Parasite Immunology 26: 2472-2464.

Korallo-Vinarskaya, N. P., B. R. Krasnov, M. V. Vinarski, G. I. Shenbrot, D. Mouillot and R. Poulin. 2009. Stability in abundance and niche breadth of gamasid mites across environmental conditions, parasite identity and host pools. Evolutionary Ecology 23: 329-345.

Krasnov, B. R., N. P. Korallo-Vinarskaya, M. V. Vinarski, G. I. Shenbrot, D. Mouillot, and R. Poulin. 2008. Searching for general patterns in parasite ecology: host identity versus environmental influence on gamasid mite assemblages in small mammals. Parasitology 135: 229-242.

Ledger, J. A. 1980. The arthropod parasites of vertebrates in Africa south of the Sahara. Volume IV. Phthiraptera (Insecta). South African Institute for Medical Research, Johannesburg, South Africa, 327 p.

Poulin, R. 2007. Evolutionary ecology of parasites. Princeton University Press, Princeton, New Jersey, 342 p.

Rósza, L., J. Reiczigel, and G. Majoros. 2000. Quantifying parasites in samples of hosts. Journal of Parasitology 86: 228-232.

Scantlebury, M., M. Maher McWilliams, N. J. Marks, J. T. A Dick, H. Edgar and H. Lutermann. 2010. Effects of life-history traits on parasite load in grey squirrels. Journal of Zoology 282: 246-255.

Scharff, A., H. Burda, F. Tenora, M. Kawalika, and V. Barus. 1997. Parasites in social subterranean Zambian mole-rats (Cryptomys ssp., Bathyergidae, Rodentia). Journal of Zoology 241: 571-577.

, O. Locker-Grütjen, M. Kawalika, and H. Burda. 2001. Natural history of the giant molerat, Cryptomys mechowi (Rodentia: Bathyergidae), from Zambia. Journal of Mammalogy 82: 1003-1015.

Till, W. 1963. Ethiopian mites of the genus Androlaelaps Berlese s. lat.(Acari: Mesostigmata). Bulletin of The British Museum of Natural History 10: 1-104.

Viljoen, H., N.C. Bennett, E.A. Ueckermann, and H. Lutermann. 2011. The role of host traits, season and group size on parasite burdens in a cooperative mammal. PloS One 6: e27003.

Vinarski, M. V., N.P. Korallo, B. R. Krasnov, G. I. Shenbrot and R. Poulin. 2007. Decay of similarity of gamasid mite assemblages parasitic on Palaearctic small mammals: Geographic distance, host-species composition or environment. Journal of Biogeography 34: 1691-1700.

Wilson, K., O. N. Bjørnstad, A. P. Dobson, S. Merler, G. Poglayen, S. E. Randolph, A. F. Read, and A. Skorping. 2001. Heterogeneities in macroparasite infections: patterns and processes. In The ecology of wildlife diseases, P. J. Hudson, A. Rizzoli, B. T. Grenfell, H. 
Heesterbeek, and A. P. Dobson (eds). Oxford University Press, New York, New York, p. 6-44. Young, A. J., M.K. Oosthuizen, H. Lutermann and N.C. Bennett, 2010. Physiological suppression eases in Damaraland mole-rat societies when ecological constraints on dispersal are relaxed. Hormones and Behavior 57: 177-183.

Zumpt, F. 1961. The arthropod parasites of vertebrates in Africa south of the Sahara. Vol. I (Chelicerata). South African Institute of Medical Research, Johannesburg, South Africa, 457 p.

$\square$ A. scapularis $\square$ A. capensis $\boldsymbol{\square}$ A. taufliebi $\square$ chiggers $\mathbf{a}$ Radfordia sp. $\square E$. hilli
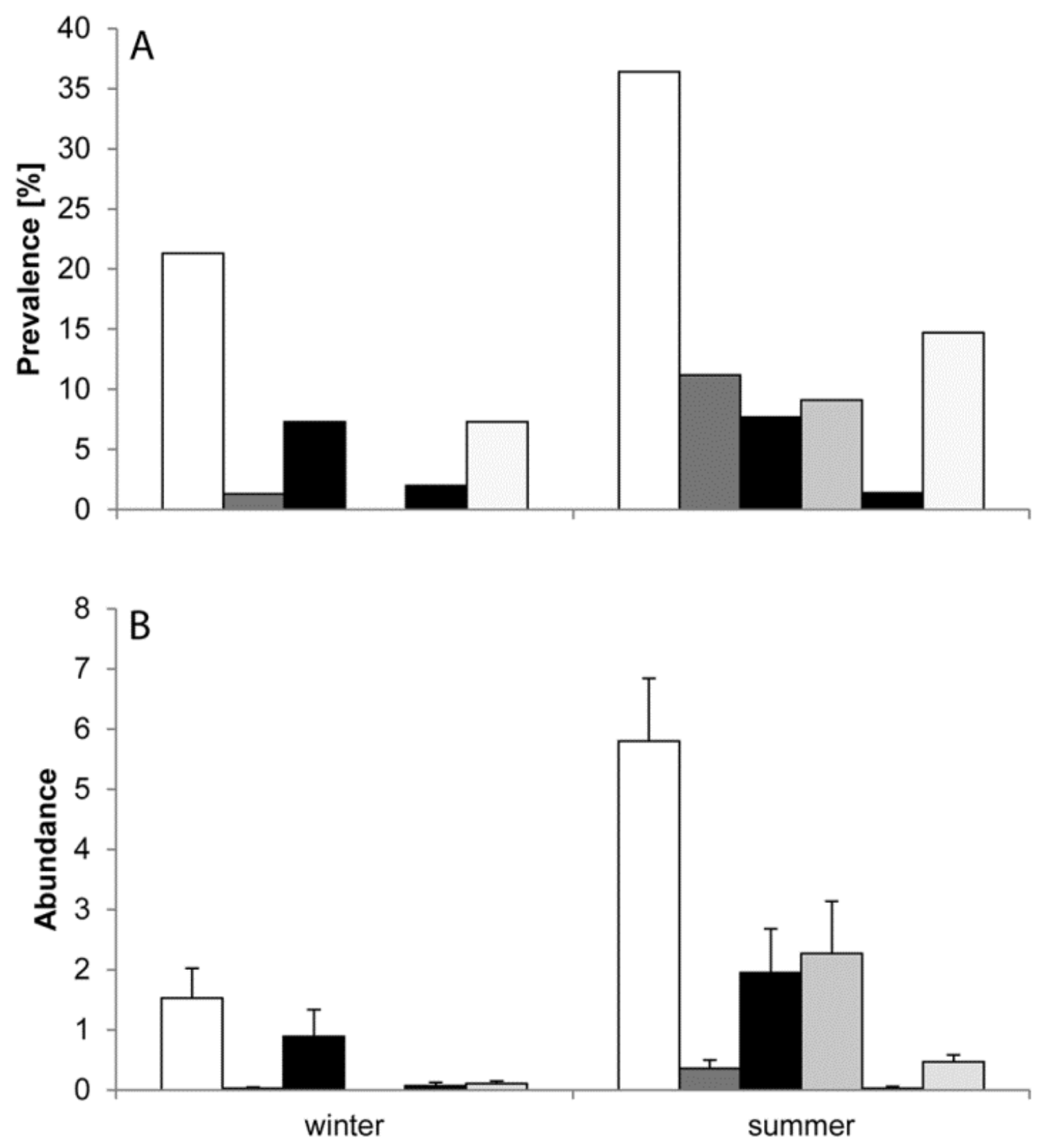

Figure 1. Seasonal variation in the ectoparasite (A) prevalence and (B) abundance of Fukomys damarensis sampled in the Khomas Province of Namibia and the Northern Cape Province of South Africa. 
Table I Arthropod species found on Fukomys damarensis sampled in the Khomas Province, Namibia and the Northern Cape Province,

\section{South Africa.}

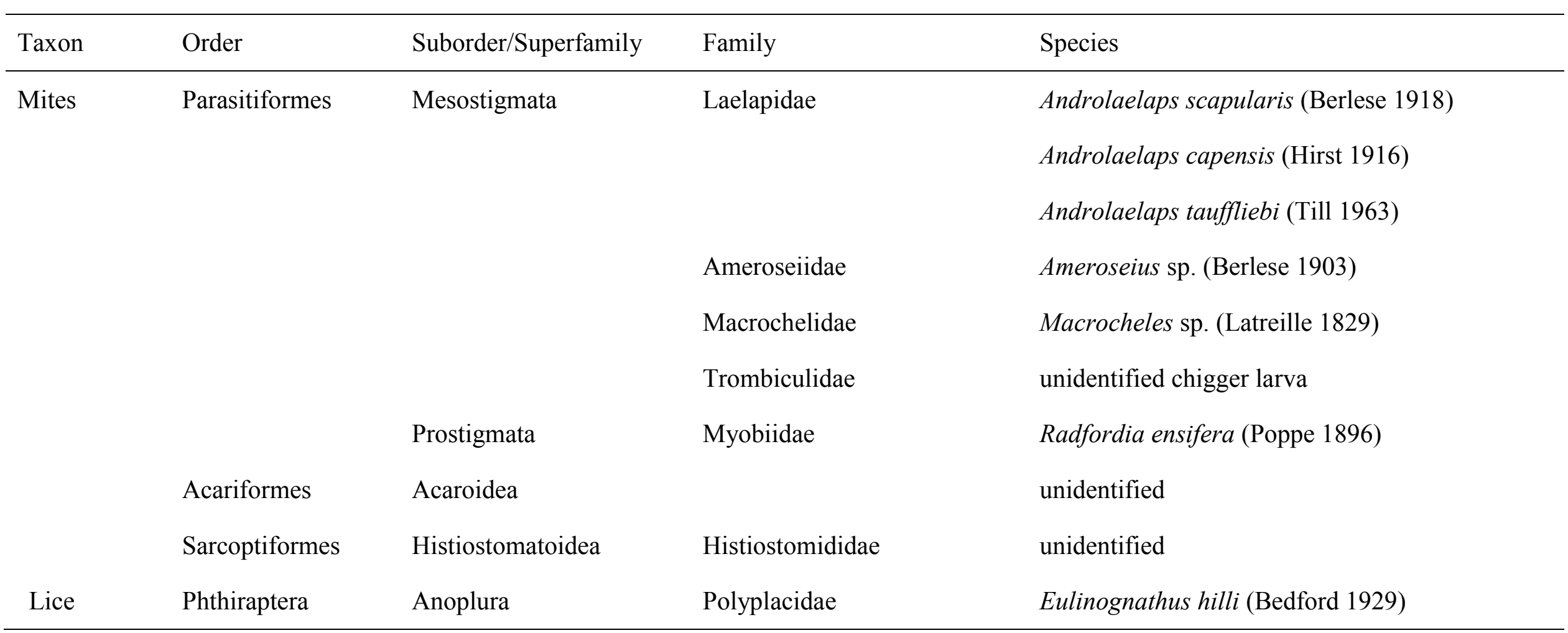


Table II. Distribution of developmental stages of the arthropod species associated with Fukomys damarensis sampled in the Khomas

Province, Namibia and the Northern Cape Province, South Africa.

\begin{tabular}{|c|c|c|c|c|c|c|c|c|}
\hline & Total & $\begin{array}{c}\text { Male } \\
\text { total }(\%)\end{array}$ & $\begin{array}{c}\text { Female } \\
\text { total }(\%)\end{array}$ & $\begin{array}{l}\text { Nymph } \\
\text { total (\%) }\end{array}$ & $\begin{array}{c}\text { Larva } \\
\text { total }(\%)\end{array}$ & $\begin{array}{l}\text { Prevalence (\%) } \\
(95 \% \text { CI) }\end{array}$ & Abundance (95\% CI) & $D$ \\
\hline Androlaelaps scapularis & 1059 & $340(32.1)$ & $275(26.0)$ & $204(19.3)$ & $2(0.2)$ & $28.7(23.6-34.1)$ & $3.61 \pm 0.58(2.47-4.76)$ & 0.880 \\
\hline Androlaelaps capensis & 55 & $22(40.0)$ & (23) 41.8 & $10(18.2)$ & - & $6.1(3.7-9.5)$ & $0.19 \pm 0.07(0.05-0.32)$ & 0.967 \\
\hline Androlaelaps tauffliebi & 412 & $206(49.4)$ & $115(27.6)$ & $96(23.0)$ & - & $7.5(4.8-11.1)$ & $1.41 \pm 0.42(0.57-2.24)$ & 0.961 \\
\hline Radfordia sp. & 17 & $4(23.5)$ & $13(76.5)$ & - & - & $1.7(0.6-3.9)$ & $0.05 \pm 0.03(-0.01-0.12)$ & 0.987 \\
\hline chigger & 324 & - & - & - & $(100.0)$ & $4.4(2.4-7.5)$ & $1.11 \pm 0.43(0.26-1.95)$ & 0.976 \\
\hline Ameroseius spp. & 72 & $2(2.8)$ & $9(12.5)$ & $29(33.3)$ & $32(51.4)$ & $3.4(1.7-6.2)$ & $0.25 \pm 0.22(-0.18-0.67)$ & 0.989 \\
\hline Acardiodea $^{\mathrm{a}}$ & 12 &.$/$ &. &. &.$/$ & 0.3 & $0.04 \pm 0.04$ & - \\
\hline Macrocheles spp. ${ }^{\text {a }}$ & 1 & - & 100 & - & - & 0.3 & $0.00 \pm 0.003$ & - \\
\hline Histiostomidaedae $^{a}$ & 3 & - & 100 & - & - & 0.3 & $0.01 \pm 0.01$ & - \\
\hline Eulinognathus hilli & 84 &.$/$ &.$/$ &.$/$ &.$/$ & $10.9(7.6-15.1)$ & $0.29 \pm 0.06(0.17-0.40)$ & 0.927 \\
\hline
\end{tabular}


Table III. Results for the comparison between seasons and sexes of prevalence and abundance of ectoparasites sampled in the Khomas Province, Namibia and the Northern Cape Province, South Africa.

\begin{tabular}{|c|c|c|c|c|c|}
\hline & \multirow[t]{2}{*}{ Taxon } & \multicolumn{2}{|l|}{ Prevalence } & \multicolumn{2}{|l|}{ Abundance } \\
\hline & & $\chi^{2}$ & $\mathrm{p}$ & $\mathrm{U}$ & $\mathrm{p}$ \\
\hline \multirow{5}{*}{ 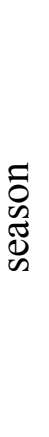 } & Androlaelaps scapularis & 8.087 & 0.004 & $12,363.0$ & 0.001 \\
\hline & Androlaelaps capensis & 12.332 & $<0.0001$ & $11,776.0$ & $<0.0001$ \\
\hline & Androlaelaps tauffliebi & 0.014 & 0.907 & $10,798.0$ & 0.826 \\
\hline & chigger & 14.269 & $<0.0001$ & $11,700.0$ & $<0.0001$ \\
\hline & Eulinognathus hilli & 4.067 & 0.044 & 11.575 .0 & 0.030 \\
\hline \multirow{5}{*}{$\underset{d}{凶}$} & Androlaelaps scapularis & 0.072 & 0.789 & $4,948.0$ & 0.670 \\
\hline & Androlaelaps capensis & 0.907 & 0.454 & 4.945 .0 & 0.338 \\
\hline & Androlaelaps tauffliebi & 0.907 & 0.454 & 4.941 .0 & 0.356 \\
\hline & chigger $^{\mathrm{a}}$ & - & - & - & - \\
\hline & Eulinognathus hilli & 2.402 & 0.192 & $4,595.5$ & 0.134 \\
\hline
\end{tabular}

U: test statistic for the Mann-Whitney U-test. ${ }^{\text {a }}$ : chiggers were absent in the individuals included in the smaller sample size and hence this analyses could not be carried out. 